\title{
Improving the Ratio of Monacolin K to Citrinin Production of Monascus purpureus NTU 568 under Dioscorea Medium through the Mediation of pH Value and Ethanol Addition
}

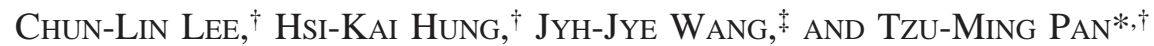 \\ Institute of Microbiology and Biochemistry, National Taiwan University, Taipei, Taiwan, Republic of \\ China, and Department of Biotechnology, Tajen University, Pingdon, Taiwan, Republic of China
}

\begin{abstract}
Using dioscorea root as substrate of Monascus species was found to stimulate monacolin $\mathrm{K}$ (cholesterol-lowering agent) formation in our previous study, but the mycotoxin-citrinin has never been studied. This study used dioscorea root as the liquid medium to culture Monascus purpureus NTU 568 using a $6.6 \mathrm{~L}$ jar fermentor. Culture $\mathrm{pH}$ value, dioscorea concentration, and ethanol concentration were used as the factors of response surface methodology (RSM) to investigate the optimal culture condition for high monacolin $\mathrm{K}$ production and low citrinin formation. Monacolin $\mathrm{K}$ and citrinin formation of $M$. purpureus NTU 568 under submerged dioscorea medium were respectively found to be significantly formed by $148 \%$ and $147 \%$, as compared to that under submerged rice medium. The reason is due to the $\mathrm{pH}$ value (3.5) of dioscorea medium involved in the formation of Monascus cell amount and secondary metabolite. RSM results further indicated that lowering the $\mathrm{pH}$ value to 2.5 would result in high monacolin $\mathrm{K}$ and citrinin concentrations as well as high biomass in fixed dioscorea amount, implying that $\mathrm{pH}$ value may stimulate the formation of monacolin $\mathrm{K}$ and citrinin through increasing Monascus cell amount. Lowering dioscorea and ethanol concentration was able to increase the ratio of monacolin $\mathrm{K}$ level to citrinin level. The optimal culture condition $(\mathrm{pH} 5.7$, $1 \%$ dioscorea concentration, and $0.5 \%$ ethanol concentration) would increase monacolin $\mathrm{K}$ levels to $27.9 \mathrm{mg} / \mathrm{g}$ (by $47 \%$ ) and decrease citrinin level to $2.15 \mu \mathrm{g} / \mathrm{g}$ (by 54\%), as compared to control

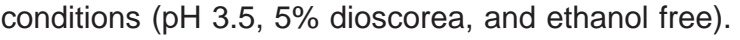

KEYWORDS: Monascus; dioscorea; monacolin; citrinin; response surface methodology

\section{INTRODUCTION}

Monascus species has been used as the traditional food fungus in Eastern Asia for several centuries. Since the worthful secondary metabolite, monacolin $\mathrm{K}$, was found to inhibit the biosynthesis of cholesterol, Monascus-fermented rice know as red mold rice (RMR) was gradually developed as the popular functional food for hypolipidemia $(1,2)$. However, red mold dioscorea (RMD) known as Monascus-fermented dioscorea is a novel and worthful Monascus-fermented product. Our previous study found that higher monacolin $\mathrm{K}$ production could be obtained in the RMD. In addition, monascin, a Monascus yellow pigment with anti-inflammatory potential, would be significantly formed and substitute for the red pigment as the major pigment of RMD (3). Although dioscorea substrate causes Monascus species to form higher monacolin $\mathrm{K}$ production, another secondary metabolite, citrinin, a mycotoxin with hepatotoxicity and nephrotoxicity, is probable to be formed with the increase of monacolin $\mathrm{K}$ and pigment $(4,5)$. The investigation of citrinin

* Author to whom correspondence should be addressed [telephone +886-2-3366-4519; fax +886-2-2362-7044; e-mail tmpan@ntu.edu.tw].

National Taiwan University.

Tajen University. formation of RMD has never been mentioned in current studies. Monacolin K production is the marker for the worth of Monascus product, but citrinin concentration is related to the food safety. Investigating a culture condition for obtaining the RMD with high monacolin $\mathrm{K}$ and low citrinin levels should be an important topic in the development of Monascus functional food.

The composition of starch or the type of carbon source would directly affect the growth of Monascus species $(6,7)$. Dioscorea species is a member of the monocotyledonous family Dioscoreace$a e$. Over $70 \%$ of starch was included in the dried dioscorea. Amylose is the major type of starch in dioscorea, and its content in the dioscorea is more than that in the rice grain $(8)$. The amylose starch is also suggested as the suitable carbon source to be used by microorganism (3). In general, amylose molecules consisting of single mostly unbranched chains with 500-20 000 $\alpha$-(1-4)-D-glucose units decomposed easily and were used by microorganism (9). This characteristic may result in a comfortable environment for Monascus species to grow. In addition, mucilage is an important material in dioscorea, which includes various kinds of amino acids (aspartic acid, glutamic acid, leucine, glycine, etc.) and carbohydrates (mannose, arabinose, 
glucose, xylose, and rhamnose) $(10,11)$. Therefore, a large amount of carbon and nitrogen sources in the mucilage of dioscorea is enough to maintain the growth of Monascus species.

The above description indicated that many components of dioscorea were the suitable carbon or nitrogen source for the use of Monascus species (3). Although dioscorea could be the suitable substrate for the growth of Monascus species, culture condition would significantly affect protein expression and the levels of the secondary metabolite of Monascus species (12). Moreover, the different substrates would use significantly different culture conditions and form different metabolites for the fermentation. Even though the culture condition of Monascus species under rice substrate has been studied by several researchers $(4,10,11)$, the different substrate should lead to significantly different results on the metabolism and production of monacolin $\mathrm{K}$ and citrinin.

Citrinin, monacolin $\mathrm{K}$, and pigments all were derived from polyketide, so these metabolites levels should be easily affected by influencing the polyketide biosynthesis pathway $(13,14)$. Our previous studies found that RMD includes high levels of yellow and orange pigment, however, that resulted from the dioscorea substrate with lower $\mathrm{pH}$ value (3.0) (3). The commercial dry dioscorea have a lower $\mathrm{pH}$ value, because the fresh dioscorea have been immersed with citrate solution for the prevention of browning (15). Although the dioscorea have a lower $\mathrm{pH}$ value, the acidic dioscorea is suitable for the growth of Monascus species. Monascus species grow at the $\mathrm{pH}$ value from 2.5 to 10.0 , but the various $\mathrm{pH}$ values would result in the formation of various metabolite (16). RMR and RMD have been found to have a significant difference on the formation of pigments because of $\mathrm{pH}$ value. However, it should be further investigated whether the enhanced monacolin $\mathrm{K}$ level caused by dioscorea substrate is associated with low $\mathrm{pH}$ value or not.

In addition to the $\mathrm{pH}$ value, many culture conditions are also proven to affect citrinin and monacolin $\mathrm{K}$ formation of $\mathrm{Mo}$ nascus species (4). Various species of dioscorea have different character, so the optimal dioscorea species for the fermentation of Monascus species should be studied. Further, substrate concentration would affect the concentration of target product if that is too much to be completely consumed or not enough for the growth of Monascus species. Regarding the condition for lowering citrinin levels, ethanol added has been used to repress citrinin formation under the solid fermentation of Monascus species $(4,17)$. According to the above description, dioscorea species, substrate concentration, $\mathrm{pH}$ value, and ethanol added are regarded as the influential factors for altering monacolin $\mathrm{K}$ and citrinin formation of Monascus species under submerged culture. Monascus purpureus NTU 568 was selected as the strain to ferment dioscorea medium using a jar fermentor. This study first examined the effect of these condition factors on monacolin K and citrinin levels of RMD, respectively, and further used response surface methodology (RSM) to investigate the optimal culture condition for obtaining the RMD with higher monacolin $\mathrm{K}$ and lower citrinin levels.

\section{MATERIALS AND METHODS}

Chemicals. Monacolin K (mevanolin) and citrinin were purchased from Sigma Chemical Co. (St. Louis, MO). LC grade acetonitrile was purchased from Merck Co. (Darmstadat, Germany). Tryptone, yeast extract, peptone, malt extract, PDA broth, and Bacto-agar were purchased from Difco Co. (Detroit, MI).

Microorganism and Seed Cultures. M. purpureus NTU 568 is a mutant with high monacolin K production. Its fermented RMR has been proven to have a hypolipidemic effect in hyperlipidemic hamster model by our previous studies (1). The other strains including Monascus sp.
Table 1. Process Variables and Levels in the Three-Variables Three-Levels Response Surface Design

\begin{tabular}{lclll}
\hline & & \multicolumn{3}{c}{ coded-variable level } \\
\cline { 3 - 5 } \multicolumn{1}{c}{ variable } & symbol & -1 & 0 & 1 \\
\hline $\mathrm{pH}$ value & $X_{1}$ & 2.5 & 5.0 & 7.5 \\
dioscorea concentration (\%) & $X_{2}$ & 1 & 3 & 5 \\
ethanol concentration (\%) & $X_{3}$ & 0.5 & 1.0 & 1.5 \\
\hline
\end{tabular}

Table 2. Process Variables and Levels in the Three-Factor Three-Levels Response Surface Design of Secondary Metabolites Experiment

\begin{tabular}{clcc}
\hline & \multicolumn{3}{c}{ independent variables (coded-level) } \\
\cline { 2 - 4 } runs & pH value & dioscorea $(\%)$ & ethanol $(\%)$ \\
\hline 1 & $7.5(1)$ & $5(1)$ & $1.0(0)$ \\
2 & $7.5(1)$ & $1(-1)$ & $1.0(0)$ \\
3 & $2.5(-1)$ & $5(1)$ & $1.0(0)$ \\
4 & $2.5(-1)$ & $1(-1)$ & $1.0(0)$ \\
5 & $7.5(1)$ & $3(0)$ & $1.5(1)$ \\
6 & $7.5(1)$ & $3(0)$ & $0.5(-1)$ \\
7 & $2.5(-1)$ & $3(0)$ & $1.5(1)$ \\
8 & $2.5(-1)$ & $3(0)$ & $0.5(-1)$ \\
9 & $5.0(0)$ & $5(1)$ & $1.5(1)$ \\
10 & $5.0(0)$ & $5(1)$ & $0.5(-1)$ \\
11 & $5.0(0)$ & $1(-1)$ & $1.5(1)$ \\
12 & $5.0(0)$ & $1(-1)$ & $0.5(-1)$ \\
13 & $5.0(0)$ & $3(0)$ & $1.0(0)$ \\
14 & $5.0(0)$ & $3(0)$ & $1.0(0)$ \\
15 & $5.0(0)$ & $3(0)$ & $1.0(0)$ \\
\hline
\end{tabular}

CA 505, Monascus sp. CH 001, M. purpureus NTU 601, M. purpureus NTU 301, M. anka M13, and Monascus sp. KT were isolated from red mold rice. The culture strains were maintained on Potato Dextrose Agar (PDA) slanted at $10{ }^{\circ} \mathrm{C}$ and transferred monthly.

Source of Dioscorea and Rice. Dry dioscorea root slice (Dioscorea batatas Dence, $D$. alata L Chungkuochang, D. alata L Kaotien, $D$. alata $\mathrm{L}$ Shansan, and D. alata $\mathrm{L}$ var. purpurea) were provided by the Taichung District Agricultural Research and Extension Station, Council of Agriculture, Executive Yuan (DARES, Taichung, Taiwain). The long-grain rice (Ipomoea batatas) was purchased from a local supermarket (Taipei, Taiwan).

Seed Culture. Dry dioscorea root or rice was milled into powder (60-80 mesh) and used as the substrates of seed culture and submerged fermentation. The media of seed culture and submerged fermentation were prepared with the same species of dioscorea and rice. Seed cultures were prepared by transferring a loopful of spore from the PDA agar slant into a $500 \mathrm{~mL}$ Hinton flask containing $100-\mathrm{mL}$ of $5 \%$ dioscorea medium or rice medium. The cultures were incubated at $30^{\circ} \mathrm{C}$ for 48 $\mathrm{h}$ at $130 \mathrm{rpm}$.

Preparation of Culture Medium with or without Fixed pH Value. Four liters of medium including 5\% substrate powder was prepared with or without mediation of $\mathrm{pH}$ value according to the $\mathrm{pH}$ condition of fermentation. The mediation of $\mathrm{pH}$ value of dioscorea $(3.0,7.0$, or 9.0) or rice medium (3.0) was adjusted with $2.0 \mathrm{M}$ citrate solution or $1.0 \mathrm{~N}$ sodium hydroxide.

Fermentation Using a Jar Fermentor. Five percent (v/v) spore suspension $\left(10^{7}\right.$ spores $\left./ \mathrm{mL}\right)$ was transferred into a $6.6 \mathrm{~L}$ jar fermentor (Firstek Co, Taipei, Taiwan) containing $4 \mathrm{~L}$ of medium. Fermentation with or without fixed $\mathrm{pH}$ value was carried out with aeration rate at 4 vvm, $30^{\circ} \mathrm{C}$, and agitation at $200 \mathrm{rpm}$ for 12 days. The fixed $\mathrm{pH}$ value $(3.0,7.0$, or 9.0$)$ was maintained with $2.0 \mathrm{M}$ citrate solution or $1.0 \mathrm{~N}$ sodium hydroxide during the whole stage of RMD and RMR fermentation. After fermentation, the RMD or RMR was collected and dried at $55{ }^{\circ} \mathrm{C}$ for $48 \mathrm{~h}$ and then weighted the total dry biomass for the calculation of the ratio of dry biomass weight to dioscorea added weight (B/D ratio).

Determination of Monacolin $\mathrm{K}$ and Citrinin Levels. One gram of dried RMR or RMD samples was extracted with $10 \mathrm{~mL}$ of ethanol 


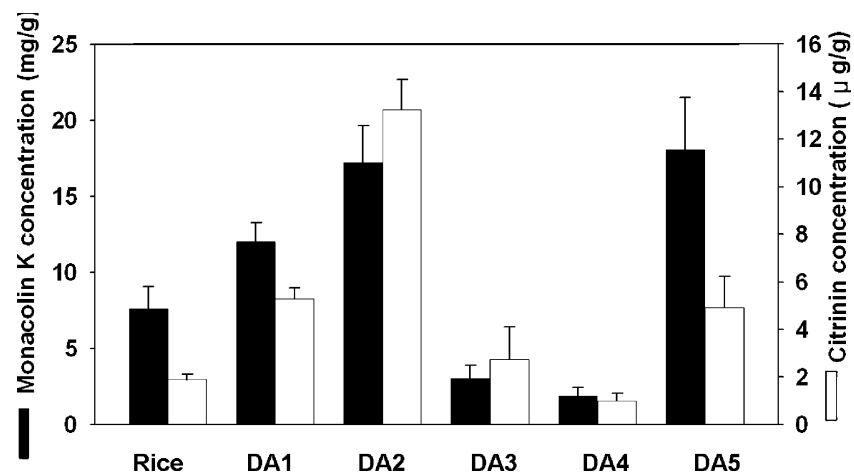

Figure 1. The effect of various species of dioscorea on monacolin $\mathrm{K}$ and citrinin levels by $M$. purpureus NTU 568. Fermentation was carried out using a $6.6 \mathrm{~L}$ jar fermentor containing $4 \mathrm{~L}$ of dioscorea medium $(5 \%)$ at $30{ }^{\circ} \mathrm{C}, 4 \mathrm{vvm}$, and $200 \mathrm{rpm}$ for 12 days $(n=3)$. DA1, D. alata $\mathrm{L}$ var. purpurea; DA2, D. alata $\mathrm{L}$ Kaotien; DA3, D. alata $\mathrm{L}$ Shansan; DA4, D. alata L Chungkuochang; DA5, Dioscorea batatas Dence.

at $65{ }^{\circ} \mathrm{C}$ for $30 \mathrm{~min}(18)$. The extracts $(10 \% \mathrm{w} / \mathrm{v})$ were further filtered with $0.45 \mu \mathrm{m}$ filter and analyzed by HPLC. HPLC was performed according to the method described previously (18) and carried out on an HPLC system PU2089 plus (Jasco Co., Tokyo, Japan). A Discovery $\mathrm{C}_{18}$ column, $25 \mathrm{~cm} \times 4.6 \mathrm{~mm}$ i.d., $5 \mu \mathrm{m}$ (Bellefonte, $\mathrm{PA}$ ), was used as the analytical column. The mobile stage consisting of $45 \%$ water, $55 \%$ acetonitrile, and $0.5 \%$ trifluoroacetate was eluted at a flow rate of 1.0 $\mathrm{mL} / \mathrm{min}$. Total monacolin $\mathrm{K}$ was detected using a UV detector UV2075 plus (Jasco Co.) set at $238 \mathrm{~nm}$. For citrinin analysis, the fluorescence detector FL-1 (Rainin Co, Wobum, MA) was set with an excitation wavelength of $330 \mathrm{~nm}$ and an emission wavelength of $500 \mathrm{~nm}$.

Pigment Estimation. Pigment concentrations are estimated using a spectrophotometer set at $400 \mathrm{~nm}$ for yellow pigment and $500 \mathrm{~nm}$ for red pigment. The results are expressed as optical density units per gram of dried medium multiplied by dilution factor (19).

Design of Experiments. To identify the optimum conditions, a BoxBehnken design (20) was selected. The crucial factors involved are $\mathrm{pH}$ value $\left(X_{1}\right)$, dioscorea concentration $\left(X_{2}\right)$, and the ethanol concentration $\left(X_{3}\right)$. These factors, and the level at which the experiments were carried out, are given in Tables 1and $\mathbf{2}$. A total of 15 runs with center points were generated. The central point of the design arrangement decided on was: $\mathrm{pH}$ value 5.0; dioscorea concentration 3\%; ethanol added $1 \%$. Control conditions were: $\mathrm{pH}$ value 3.0 ; dioscorea concentration 5\%; ethanol free.

Response Surface Methodology. The analysis of data was carried out using response surface regression (RSREG) in Statistical Analysis System (SAS, Cary, NC). A second-order model was employed to fit the data individually for the responses $Y_{1}$ (monacolin $\mathrm{K}$ level), $Y_{2}$ (citrinin level), $Y_{3}$ (B/D ratio), and $Y_{4}$ (monacolin $\mathrm{K}$ level (mg/g)/citrinin level $(\mu \mathrm{g} / \mathrm{g})$ ratio, $\mathrm{M} / \mathrm{C}$ ratio) by the general mode $(21)$, with three factors, each factor coded to be in the range of $-1,0,+1$.

$$
\begin{aligned}
Y=A_{0}+A_{1} X_{1}+A_{2} X_{2}+ & A_{3} X_{3}+A_{11}\left(X_{1}\right)^{2}+A_{22}\left(X_{2}\right)^{2}+ \\
& A_{33}\left(X_{3}\right)^{2}+A_{12} X_{1} X_{2}+A_{13} X_{1} X_{3}+A_{23} X_{2} X_{3}
\end{aligned}
$$

The coded points for this experimental design are given in Tables $\mathbf{1}$ and 2 .

The model was evaluated in terms of statistically significant coefficient, $r^{2}$, and $p$ values.

\section{RESULTS AND DISCUSSION}

Effect of Various Species of Dioscorea on Monacolin K and Citrinin Levels. Dioscorea may provide a good environment for monacolin $\mathrm{K}$ formation of Monascus species. In this study, various species of dioscorea were used as the medium of $M$. purpureus NTU 568 to test the monacolin $\mathrm{K}$ and citrinin production. The results were shown as Figure 1; various dioscorea species would result in a significant difference in monacolin $\mathrm{K}$ and citrinin levels. As compared to rice substrate, monacolin $\mathrm{K}$ production can be increased under DA1 (by $57.7 \%$ ), DA2 (by 125.7\%), and DA5 (by 148.3\%) substrate, and decreased under DA3 (60.5\%) and DA4 (75.3\%) substrate. Various dioscorea species caused M. purpureus NTU 568 much formation of monacolin $\mathrm{K}$, but also resulted in different increase levels on citrinin formation. Citrinin levels would be significantly increased by $180 \%$ and $600 \%$ under DA1 and DA2 substrate, and the increased ratio was higher than monacolin $\mathrm{K}$. However, the results clearly clarified that DA5 (Dioscorea batatas Dence) was the most suitable substrate for obtaining higher monacolin $\mathrm{K}$ level and lower citrinin level.

Monacolin K Level of Various Monascus Species under Submerged Fermentation. Our previous study proved that using the solid fermentation method to produce RMD leads to higher monacolin $\mathrm{K}$ and monascin production (3). The medium of submerged culture only consisted of 5\% dioscorea or rice powder to use a simple composition of medium to find out the reason why dioscorea stimulates monacolin $\mathrm{K}$ formation. This study investigated whether submerged culture using a jar fermentor was also able to exhibit the tendency toward the formation of monacolin $\mathrm{K}$ and monascin. As shown in Table 3, submerged culture exhibited higher monacolin $\mathrm{K}$ and citrinin production as well as yellow pigment under dioscorea medium than that under rice medium. Furthermore, submerged culture of Monascus species would perform stable and higher reproducibility on the production of secondary metabolites than solid culture and so was more suitable for the investigation of culture condition.

Effect of Dioscorea Medium and Rice Medium on the Change of Monacolin K Formation and pH Value. This study

\begin{tabular}{|c|c|c|c|c|c|}
\hline species & substrate & $\underset{(\mathrm{mg} / \mathrm{g})}{\operatorname{monacolin} \mathrm{K}}$ & $\begin{array}{l}\text { citrinin } \\
(\mu \mathrm{g} / \mathrm{g})\end{array}$ & $\begin{array}{l}\text { red pigment } \\
\quad\left(A_{500} / g\right)\end{array}$ & $\begin{array}{c}\text { yellow pigment } \\
\qquad\left(A_{400} / g\right)\end{array}$ \\
\hline \multirow[t]{2}{*}{ M. sp. CA 505} & rice & 2.42 & 0.20 & 112 & 98.4 \\
\hline & dioscorea & 8.45 & 0.93 & 105 & 132 \\
\hline M. purpureus & rice & 7.62 & 1.89 & 143 & 120 \\
\hline NTU 568 & dioscorea & 18.92 & 4.67 & 115 & 135 \\
\hline \multirow[t]{2}{*}{ M. sp. CH 001} & rice & 5.92 & 2.52 & 140 & 110 \\
\hline & dioscorea & 17.65 & 8.70 & 120 & 149 \\
\hline M. purpureus & rice & 0.58 & 0.46 & 72.0 & 60.0 \\
\hline NTU 601 & dioscorea & 3.54 & 1.57 & 61.1 & 88.3 \\
\hline M. purpureus & rice & 0.51 & 0.37 & 93.5 & 77.6 \\
\hline NTU 301 & dioscorea & 3.08 & 0.76 & 110 & 93.0 \\
\hline \multirow[t]{2}{*}{ M. anka M 13} & rice & 0.11 & 0.48 & 93.4 & 80.1 \\
\hline & dioscorea & 0.63 & 0.37 & 50.6 & 63.1 \\
\hline \multirow[t]{2}{*}{ M. sp. KT } & rice & 0.36 & 0.86 & 85.5 & 70.2 \\
\hline & dioscorea & 3.89 & 0.97 & 66.9 & 93.5 \\
\hline
\end{tabular}

Table 3. Production of the Secondary Metabolites on Rice Medium and Dioscorea Medium by Different Monascus Species 


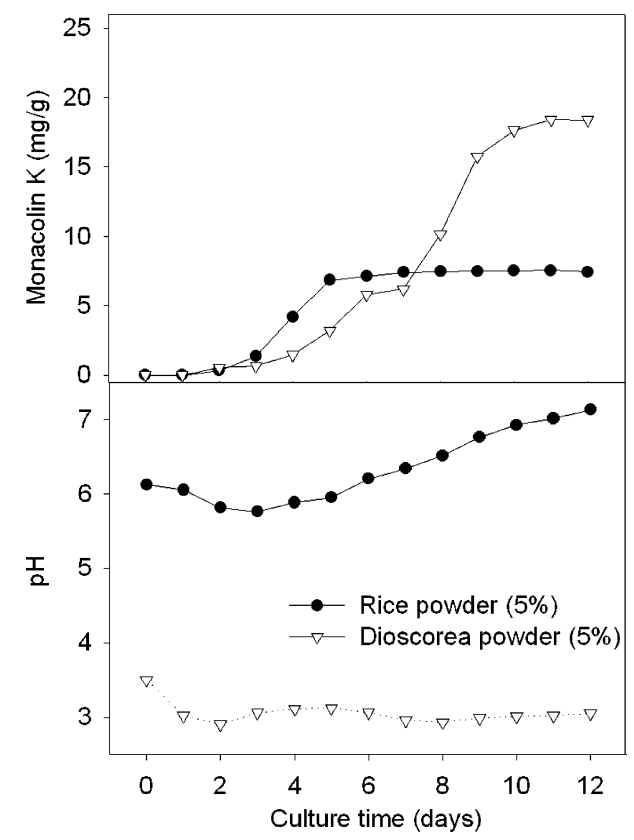

Figure 2. The comparison of the effect of dioscorea medium and rice medium on monacolin $\mathrm{K}$ formation and the change of $\mathrm{pH}$ value by $M$. purpureus NTU 568. Fermentation was carried out using a 6.6-L jar fermentor containing $4 \mathrm{~L}$ of medium including $5 \%$ substrate at $30^{\circ} \mathrm{C}, 4$ vvm, and $200 \mathrm{rpm}$ for 12 days $(n=3)$.

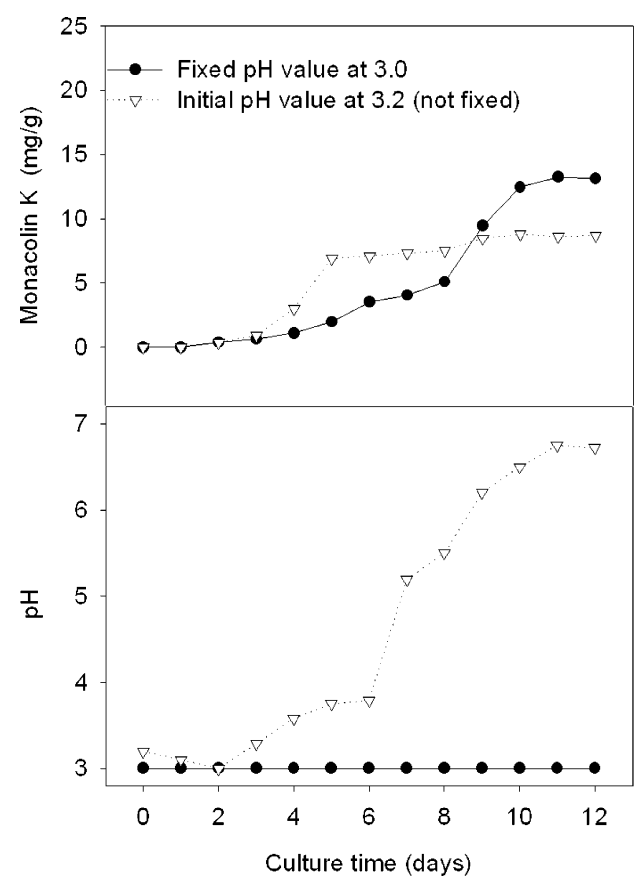

Figure 3. The comparison of the effect of rice medium with or without fixed $\mathrm{pH}$ value at 3.0 on monacolin $\mathrm{K}$ formation and the change of $\mathrm{pH}$ value by $M$. purpureus NTU 568. Fermentation was carried out using a 6.6- $\mathrm{L}$ jar fermentor containing $4 \mathrm{~L}$ of medium including $5 \%$ substrate at $30{ }^{\circ} \mathrm{C}, 4 \mathrm{vvm}$, and $200 \mathrm{rpm}$ for 12 days $(n=3)$.

used a jar fermentor to continuously monitor the difference on the change of secondary metabolite production and $\mathrm{pH}$ condition between using rice medium and dioscorea medium during whole Monascus fermentation. As shown in Figure 2, the two media resulted in a significant difference in the change of $\mathrm{pH}$ value during the submerged fermentation. The $\mathrm{pH}$ value of liquid rice medium without adjustment is measured among 5.6-6.6, which ranged over the general $\mathrm{pH}$ condition for the culture of
Monascus species in common with many studies $(4,6)$. During submerged culture of $M$. purpureus NTU 568 under rice medium, the $\mathrm{pH}$ value would be decreased to $5.0-5.5$ by organic acid formation in the initial stage and then gradually increased to neutral $\mathrm{pH}$ value in a later stage. However, dioscorea medium modulated the $\mathrm{pH}$ value toward a significantly different trend during submerged culture because of the citrate pretreatment of dioscorea. The initial $\mathrm{pH}$ value of the dioscorea medium is measured at 3.5 before inoculation. After inoculation, the $\mathrm{pH}$ value was decreased to 3.0 during the initial stage and then only exhibits a slight variation until the end of fermentation. Monascus species is able to grow under a wide range of $\mathrm{pH}$ values between 2.5 and 10.0. Previous researchers usually cultured Monascus species under pH 6.0-7.0 (4, 12, 22); an extreme culture condition at $\mathrm{pH} 3.0$ has never been used to culture Monascus species for produce monacolin K. Therefore, $\mathrm{pH}$ value may be an important factor for stimulating monacolin $\mathrm{K}$ and monascin.

Effect of Rice Medium with or without Fixed pH Value at 3.0 on the Change of Monacolin K Formation. To investigate whether rice medium with acid condition as dioscorea medium can stimulate monacolin $\mathrm{K}$ formation or not, the $\mathrm{pH}$ value of rice medium was acidified to 3.2 before inoculation but not modulated during whole fermentation process. As shown in Figure 3, the $\mathrm{pH}$ value would be slightly decreased in the initial stage and observably increased from the middle stage to later stage. Finally, the $\mathrm{pH}$ value of acidified rice medium would be increased to neutral 6.8, which also led to less monacolin $\mathrm{K}$ production than RMD. $M$. purpureus stops forming monacolin $\mathrm{K}$ at a level about $6.8 \mathrm{mg} / \mathrm{g}$ as the $\mathrm{pH}$ value is increased over 5.0 during the later stage. This study further fixed the $\mathrm{pH}$ value of rice medium at 3.0 by a jar fermentor during whole fermentation to parallel a fixed acidic $\mathrm{pH}$ condition of dioscorea medium. In the results, monacolin $\mathrm{K}$ formation would be increased to $13.3 \mathrm{mg} / \mathrm{g}$ under rice medium with a fixed $\mathrm{pH}$ value at 3.0 until the later fermentation stage, and its trend was similar to that under the dioscorea medium (Figure 3). In addition to monacolin $\mathrm{K}$, the appearance of the yellow pigments under acidic rice medium was also similar to that under dioscorea medium (Figure 4). In contrast, rice medium with neutral $\mathrm{pH}$ value would result in the appearance of the red pigments.

According to the above results, the acidic fermentation condition was one of the probable reasons why dioscorea resulted in higher monacolin $\mathrm{K}$ level. However, the monacolin $\mathrm{K}$ level formed under acidic rice medium was still less by $64.3 \%$ than that formed under dioscorea medium. The composition and character of dioscorea should make up for the lack of monacolin $\mathrm{K}$ formation.

Effect of Various pH Values of Dioscorea on Monacolin $\mathbf{K}$ and Citrinin Production. Although the $\mathrm{pH}$ value of dioscorea was an important factor to stimulate monacolin $\mathrm{K}$ and monascin formation in Monascus species, its influence on citrinin formation has never been reported by Monascus-related studies. The acidic ( $\mathrm{pH} 3.0)$, neutral ( $\mathrm{pH} 7.0)$, and alkaline $(\mathrm{pH}$ 9.0) dioscorea media were used to culture $M$. purpureus NTU 568 to investigate the effect of $\mathrm{pH}$ value of dioscorea medium on monacolin $\mathrm{K}$ and citrinin formation. As shown in Figure 5, monacolin $\mathrm{K}$ and citrinin formation under various $\mathrm{pH}$ values had a similar tendency toward positive production with decreasing $\mathrm{pH}$ value. Both monacolin $\mathrm{K}$ and citrinin levels produced under acidic dioscorea medium (pH 3.0) are higher by $102 \%$ and $114 \%$ than that produced under alkaline dioscorea medium (pH 9.0). 


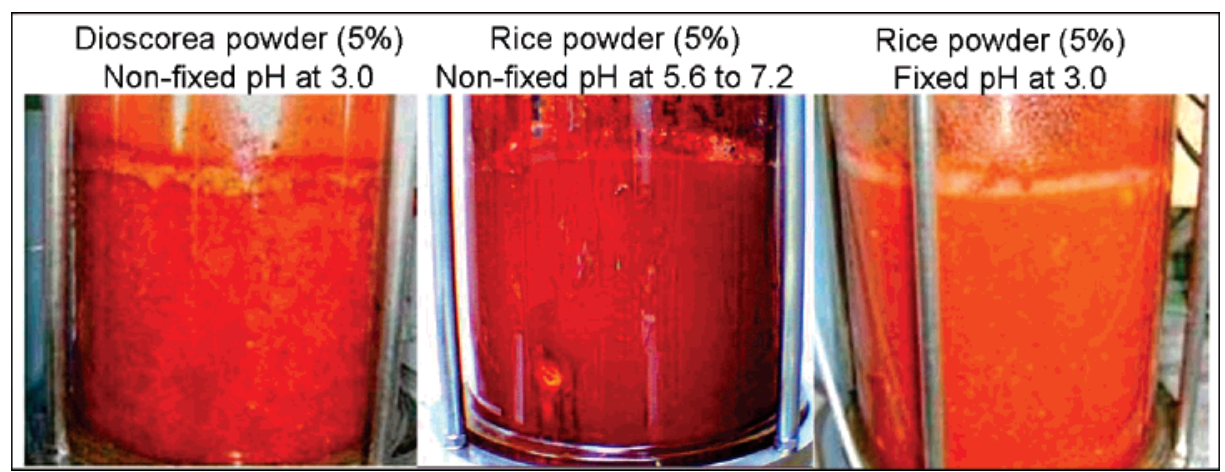

Figure 4. The comparison of the effect of dioscorea medium and rice medium with or without fixed pH value at 3.0 on the outward appearance by $M$. purpureus NTU 568. Fermentation was carried out using a 6.6-L jar fermentor containing $4 \mathrm{~L}$ of medium including $5 \%$ substrate at $30{ }^{\circ} \mathrm{C}, 4 \mathrm{vvm}$, and 200 rpm for 12 days $(n=3)$.

Table 4. Analysis of Variance for the Production of Citrinin, Monacolin K, B/D Ratio, and M/C Ratio with Various Culture Conditions ${ }^{a}$

\begin{tabular}{lccrrr}
\hline & & \multicolumn{3}{c}{ sum of square } \\
\cline { 3 - 6 } \multicolumn{1}{c}{ source } & df $b$ & monacolin K & citrinin & B/D ratio $^{c}$ & M/C ratio \\
\hline regression & 9 & 15658439 & 10124580 & 3.38 & 120.15 \\
residual & 5 & 306989 & 1942694 & 0.02 & 10.07 \\
lack of fit & 3 & 306981 & 1942674 & -0.04 & 0.06 \\
pure error & 2 & 7.84 & 19.71 & 0.65 & 1.42 \\
variability explain $\left(r^{2}\right)$ & & 0.98 & 0.84 & 0.99
\end{tabular}

\footnotetext{
${ }^{a} \mathrm{df}$ : degree of freedom. ${ }^{b}$ Analysis of variance from SAS statistics system. ${ }^{c}$ The ratio of dry biomass to added dioscorea weight. ${ }^{d}$ The ratio of monacolin $\mathrm{K}$ to citrinin level.
}

Optimum Culture Conditions Based on RSM. Design of Experiments and Model. This study used RSM to investigate optimum culture conditions taking account of three factors: culture $\mathrm{pH}$ value, dioscorea concentration, and ethanol concentration. The factors and coded values are given in Tables $\mathbf{1}$ and 2.

Regression Equation, $r^{2}$ Value of Model. Data from 15 experiments were used. The following equations, where the factors take their coded value, were obtained from regression analysis for the secondary metabolite concentrations:

$$
\begin{gathered}
\text { monacolin } \mathrm{K}(\mathrm{mg} / \mathrm{g})=15.92-23.25 X_{1}-28.06 X_{2}- \\
8.66 X_{3}-24.63\left(X_{1}\right)^{2}+16.03\left(X_{2}\right)^{2}+1.50\left(X_{3}\right)^{2}- \\
0.11 X_{1} X_{2}+11.81 X_{1} X_{3}+11.86 X_{2} X_{3}
\end{gathered}
$$

citrinin $(\mu \mathrm{g} / \mathrm{g})=18.26-5.25 X_{1}-22.13 X_{2}-5.05 X_{3}+$

$7.13\left(X_{1}\right)^{2}+4.59\left(X_{2}\right)^{2}-3.52\left(X_{3}\right)^{2}-27.96 X_{1} X_{2}+$

$$
8.42 X_{1} X_{3}+15.57 X_{2} X_{3}
$$

$$
\begin{array}{r}
\mathrm{B} / \mathrm{D} \text { ratio }=0.819-0.042 X_{1}-0.578 X_{2}+0.033 X_{3}- \\
0.064\left(X_{1}\right)^{2}+0.409\left(X_{2}\right)^{2}-0.056\left(X_{3}\right)^{2}+0.058 X_{1} X_{2}- \\
0.005 X_{1} X_{3}-0.003 X_{2} X_{3}
\end{array}
$$

$$
\begin{array}{r}
\mathrm{M} / \mathrm{C} \text { ratio }=0.895-1.498 X_{1}+0.174 X_{2}+1.027 X_{3}- \\
0.493\left(X_{1}\right)^{2}-1.492\left(X_{2}\right)^{2}+0.146\left(X_{3}\right)^{2}+3.653 X_{1} X_{2}- \\
2.114 X_{1} X_{3}+1.974 X_{2} X_{3}
\end{array}
$$

The variability in the responses accounted for by the factors ( $r^{2}$ value) for the models is given in Table 4. The $r^{2}$ values of monacolin $\mathrm{K}$ level, citrinin level, $\mathrm{B} / \mathrm{D}$ ratio, and $\mathrm{M} / \mathrm{C}$ ratio were $0.98,0.84,0.99$, and 0.92 , respectively. Also, the test statistics $p$ value for the overall regression is significant at the $5 \%$ level, which further supports that the model is adequate in approximating the response surface of the experimental design.

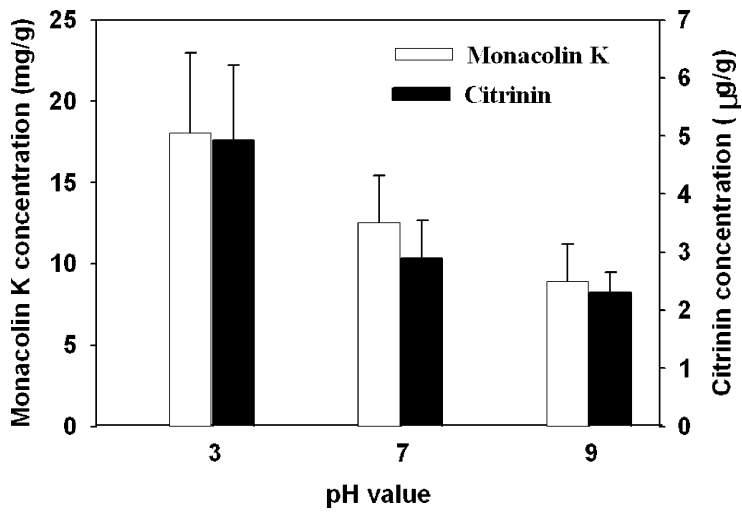

Figure 5. The effect of dioscorea medium with various $\mathrm{pH}$ values on monacolin $\mathrm{K}$ and citrinin formation by $M$. purpureus NTU 568 . Fermentation was carried out using a 6.6-L jar fermentor containing $4 \mathrm{~L}$ of medium including $5 \%$ substrate at $30{ }^{\circ} \mathrm{C}, 4 \mathrm{vvm}$, and $200 \mathrm{rpm}$ for 12 days $(n=$ 3).

Effect of the Condition Factors on Monacolin K Formation. As shown in the Figure 6, monacolin $\mathrm{K}$ production would be gradually increased with the decreasing $\mathrm{pH}$ value under lower dioscorea concentration. Although dioscorea is a suitable substrate for monacolin $\mathrm{K}$ formation, increasing dioscorea concentration contrarily gained lower monacolin $\mathrm{K}$ concentration. The reason is that Monascus species was not able to completely consume and use up too much dioscorea substrate during the fermentation stage of 12 days. The monacolin $\mathrm{K}$ concentration of total solid material would be decreased if too much unfermented dioscorea substrate remained in the medium after fermentation. However, monacolin $\mathrm{K}$ formation would be repressed by increasing ethanol concentration. According to the effects of the three factors, the curve surface figure indicates that a higher monacolin $\mathrm{K}$ level could be obtained under $\mathrm{pH} 2.5$ condition including $1 \%$ dioscorea and $0.5 \%$ ethanol. 


\section{A. Ethanol concentration $(0.5 \%)$}

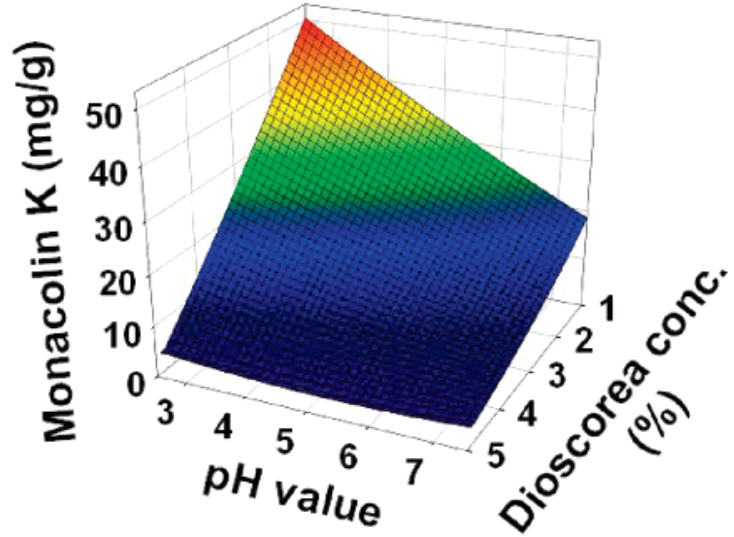

\section{B. Ethanol concentration $(\mathbf{1 . 0} \%)$}

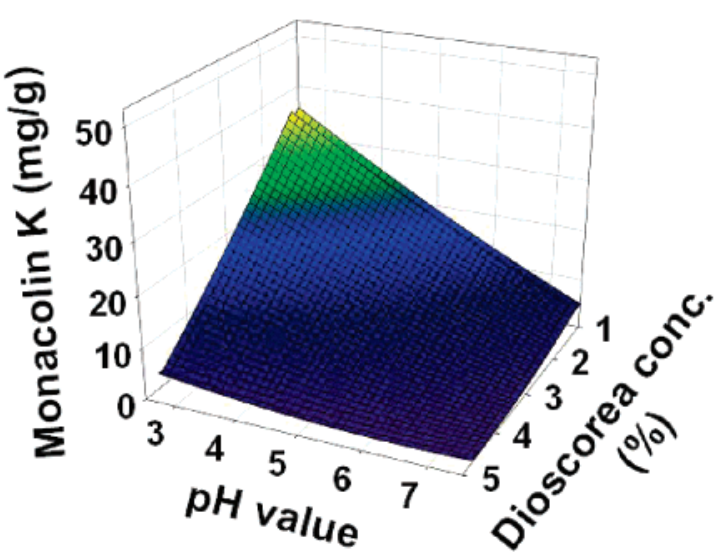

\section{Ethanol concentration (1.5\%)}

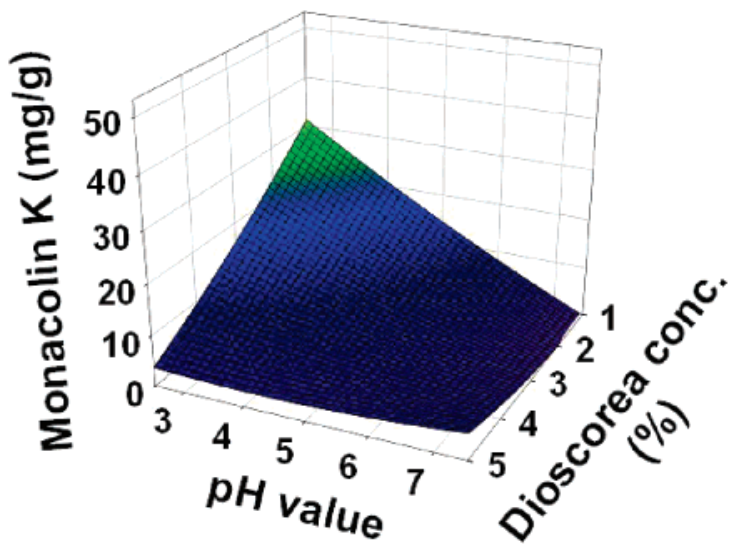

Figure 6. The response surface for the production of monacolin $\mathrm{K}$ at various $\mathrm{pH}$ values and dioscorea concentrations. Fermentation was carried out using a 6.6-L jar fermentor containing $4 \mathrm{~L}$ of medium at $30^{\circ} \mathrm{C}$ and $200 \mathrm{rpm}$ for 12 days.

Effect of the Condition Factors on Citrinin Formation. The effect of factors on citrinin formation is shown in Figure 7. The trend of citrinin formation affected by $\mathrm{pH}$ condition was similar to that of monacolin $\mathrm{K}$ formation. Citrinin level of RMD would be increased by decreasing $\mathrm{pH}$ value. Dioscorea concentration led to different results between monacolin $\mathrm{K}$ and citrinin formation. Citrinin level was stimulated to arrived at the most accumulation under $3 \%$ dioscorea concentration. Increasing ethanol concentration would also repress citrinin formation as the $\mathrm{pH}$ value was mediated between 4.0 and 7.5.

\section{A. Ethanol concentration $(0.5 \%)$}

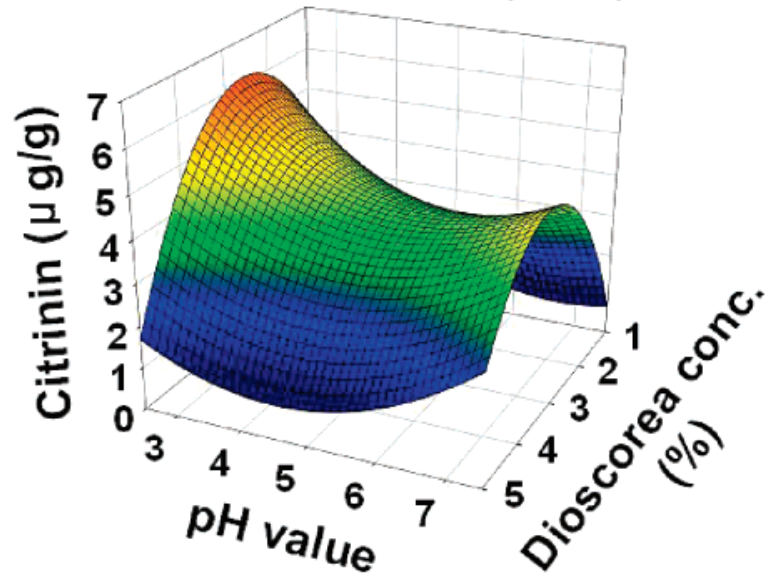

\section{B. Ethanol concentration $(1.0 \%)$}

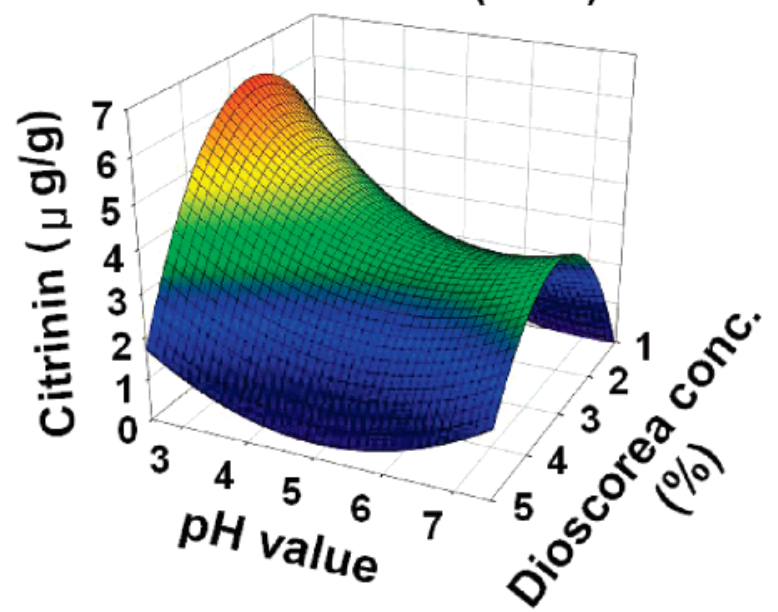

C. Ethanol concentration (1.5\%)

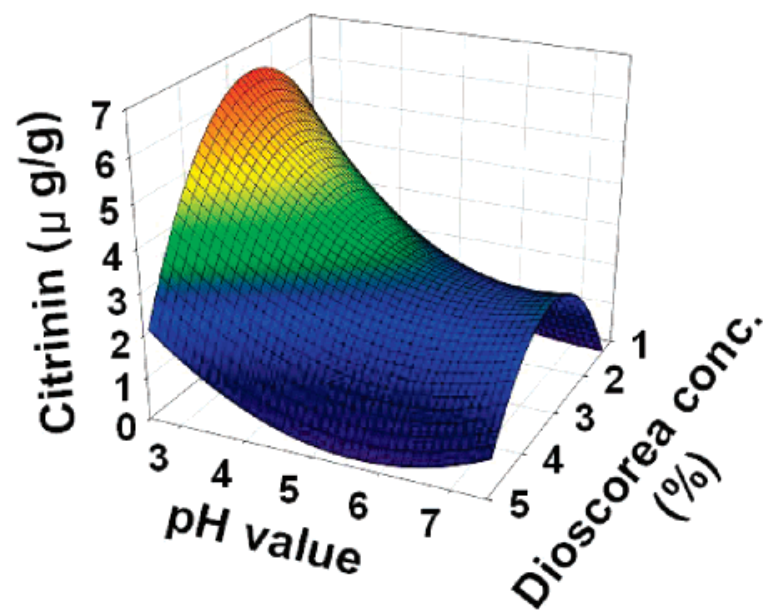

Figure 7. The response surface for the production of citrinin at various $\mathrm{pH}$ values and dioscorea concentrations. Fermentation was carried out using a 6.6-L jar fermentor containing $4 \mathrm{~L}$ of medium at $30^{\circ} \mathrm{C}$ and 200 rpm for 12 days.

Lower citrinin level was also obtained as $1.0 \%$ or $5 \%$ dioscorea concentration was used as the submerged culture medium.

Effect of the Condition Factors on the Ratio of Dry Biomass to Dioscorea Added. The effect of culture condition on the formation of total pellet per fixed dioscorea added was also mentioned in this study. The ratio of dry biomass weight 
to added dioscorea weight (B/D ratio) was used as the marker to evaluate the formation of Monascus cell amount. The increased ratio implied that more Monascus cell amount could be formed under the same amount of dioscorea added. The surface figure (Figure 8) clearly indicates that the ratio related to the formation of Monascus cell amount would be enhanced by decreasing $\mathrm{pH}$ value but not affected by the change of dioscorea concentration. According to these RSM results, monacolin $\mathrm{K}$ and citrinin formation stimulated by acidic $\mathrm{pH}$ value were due to the increase of the cell amount. In addition, ethanol added would not lead to a significant change of the ratio, suggesting that the ethanol-mediated monacolin $\mathrm{K}$ and citrinin formation may not associate with the change of Monascus cell amount, but the biosynthesis mediation of secondary metabolite.

Effect of the Condition Factors on the Ratio of Monacolin K Level to Citrinin Level. A well culture condition for Monascus-fermented product should result in higher monacolin $\mathrm{K}$ and lower citrinin concentration. In this study, the ratio of monacolin $\mathrm{K}$ level $(\mathrm{mg} / \mathrm{g})$ to citrinin level $(\mu \mathrm{g} / \mathrm{g})(\mathrm{M} / \mathrm{C}$ ratio) was calculated and used as the marker for screening the optimal culture condition. The RSM surface figures for $\mathrm{M} / \mathrm{C}$ ratio are shown as Figure 9. Dioscorea concentration resulted in a more significant difference on the change of $\mathrm{M} / \mathrm{C}$ ratio than $\mathrm{pH}$ value. Lower dioscorea concentration led to higher $\mathrm{M} / \mathrm{C}$ ratio, which indicated that higher monacolin $\mathrm{K}$ and lower citrinin levels would be gained under this culture condition. Lower $\mathrm{pH}$ value would stimulate the formation of Monascus cell amount and result in higher monacolin $\mathrm{K}$ according to the above results, but the $\mathrm{M} / \mathrm{C}$ ratio was still decreased because of the formation of higher citrinin levels (Figure 9). In addition, $0.5 \%$ ethanol concentration was the most suitable condition to gain higher $\mathrm{M} / \mathrm{C}$ ratio.

Selection for the Optimal Culture Condition through the Comprehensive Conclusion of RSM Results. To obtain the optimal culture condition, the vertical views of three surface figures including Figure 6A, 7A, and $\mathbf{9 A}$ were overlapped and then used to select the optimal culture condition for obtaining higher monacolin $\mathrm{K}$ and lower citrinin levels. The overlap figure was shown as Figure 10. Higher monacolin K level could be obtained under lower dioscorea concentration and lower $\mathrm{pH}$ value. However, to obtain RMD including lower citrinin level, both higher $\mathrm{pH}$ value and lower dioscorea concentration should be used as the culture condition. Lower dioscorea concentration was an important condition for increasing the $\mathrm{M} / \mathrm{C}$ ratio. According to these trends, $1 \%$ dioscorea concentration was selected as one of the optimal culture conditions. However, $\mathrm{pH}$ value should not be modulated too low or too high for fear of resulting in high citrinin levels or low monacolin $\mathrm{K}$ levels. According to the surface figure, the $\mathrm{pH}$ value at 5.7 was a suitable condition for obtaining higher $\mathrm{M} / \mathrm{C}$ ratio. The optimal culture condition was shown in Figure 10; culture medium including $1.0 \%$ dioscorea and $0.5 \%$ ethanol at $\mathrm{pH} 5.7$ may result in the optimal fermented product including $29.14 \mathrm{mg} / \mathrm{g}$ monacolin $\mathrm{K}$ and $1.91 \mu \mathrm{g} / \mathrm{g}$ citrinin. The optimal culture condition based on RSM result was further used to verify the production of monacolin $\mathrm{K}$ and citrinin. As shown in Table 5, high monacolin $\mathrm{K}$ level at $27.90 \mathrm{mg} / \mathrm{g}$ and low citrinin level at 2.15 $\mu \mathrm{g} / \mathrm{g}$ would be obtained in the RMD fermentation using the $\mathrm{RSM}$ condition. The M/C ratio was also increased from 4.05 to 12.98 using RSM condition.

The formation of citrinin is always a troublesome problem for the development of Monascus functional food (23). The safety of Monascus product containing high citrinin level was

\section{A. Ethanol concentration $(0.5 \%)$}

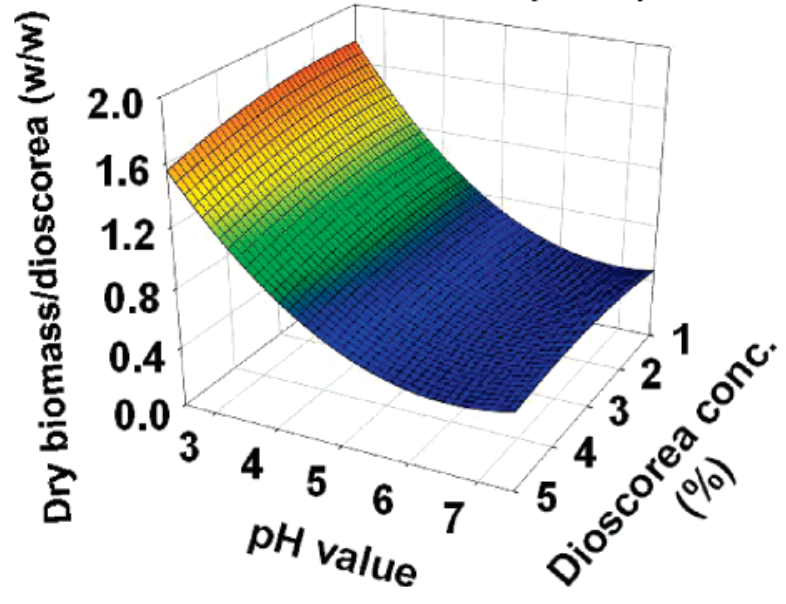

B. Ethanol concentration $(1.0 \%)$

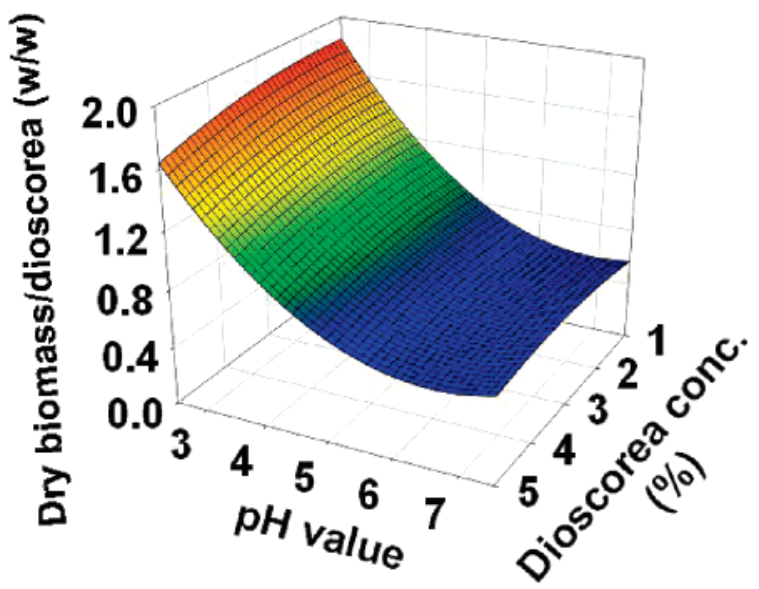

C. Ethanol concentration (1.5\%)

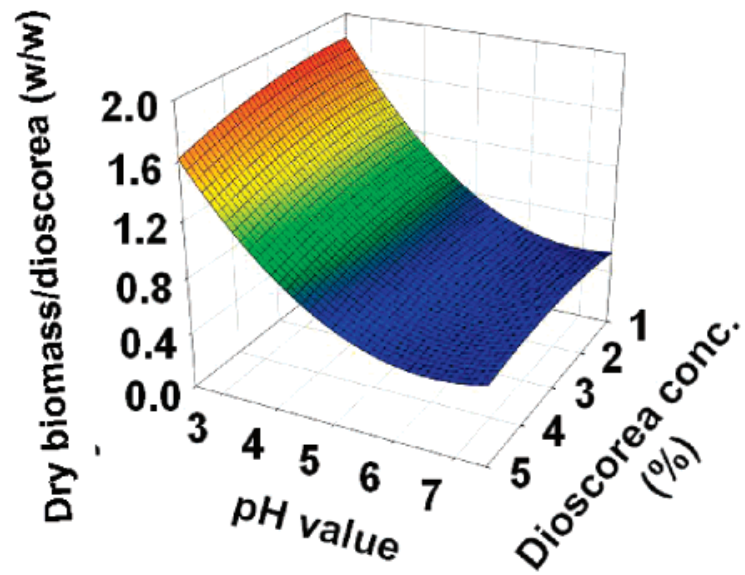

Figure 8. The response surface for the ratio of dry biomass to dioscorea weight at various $\mathrm{pH}$ values and dioscorea concentrations. Fermentation was carried out using a 6.6-L jar fermentor containing $4 \mathrm{~L}$ of medium at $30{ }^{\circ} \mathrm{C}$ and $200 \mathrm{rpm}$ for 12 days.

a concern even though many health functions including hypolipidemia, hypotensive, anti-fatigue, and anti-cancer have been reported by many researchers and developed as the popular commercial product $(1,24-26)$. Although previous studies have proven that monacolin $\mathrm{K}$ and monascin production would be increased under solid dioscorea substrate (3), more citrinin formation was found to be stimulated under submerged dioscorea 


\section{A. Ethanol concentration $(0.5 \%)$}

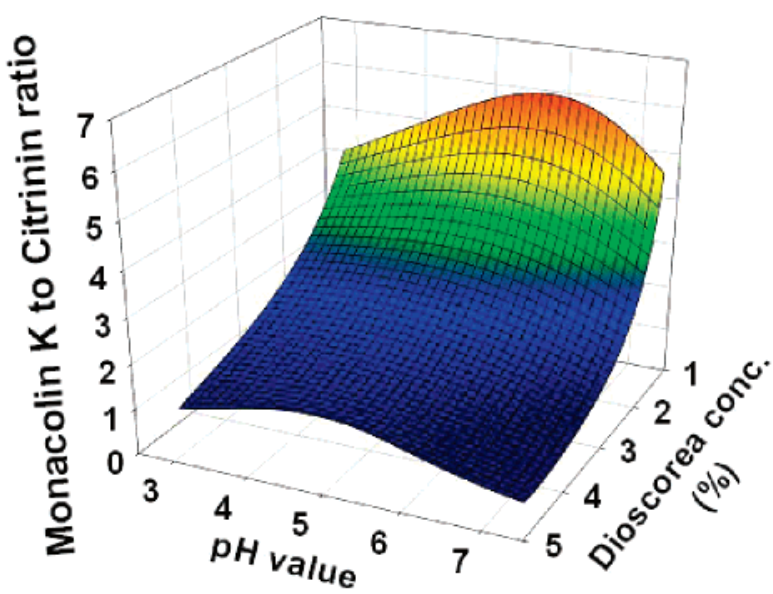

\section{B. Ethanol concentration $(1.0 \%)$}

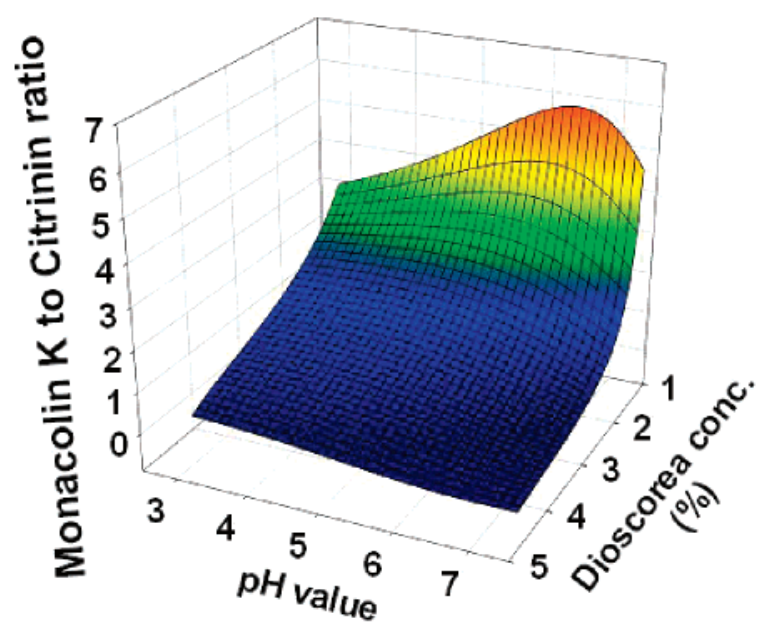

\section{Ethanol concentration (1.5\%)}

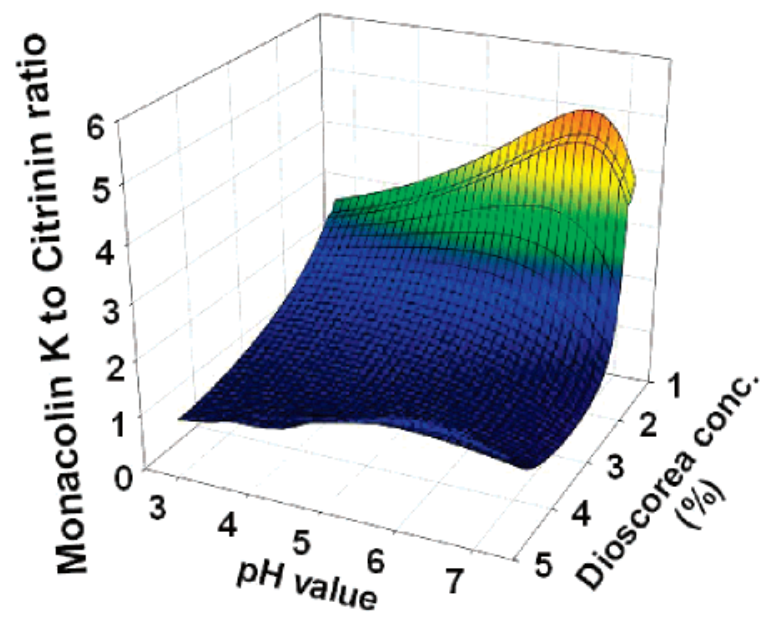

Figure 9. The response surface for the ratio of monacolin $\mathrm{K}$ to citrinin levels at various $\mathrm{pH}$ values and dioscorea concentrations. Fermentation was carried out using a 6.6-L jar fermentor containing $4 \mathrm{~L}$ of medium at $30{ }^{\circ} \mathrm{C}$ and $200 \mathrm{rpm}$ for 12 days.

medium by this study (Figure 1). As compared to previous studies (3), the formation of secondary metabolites under solid

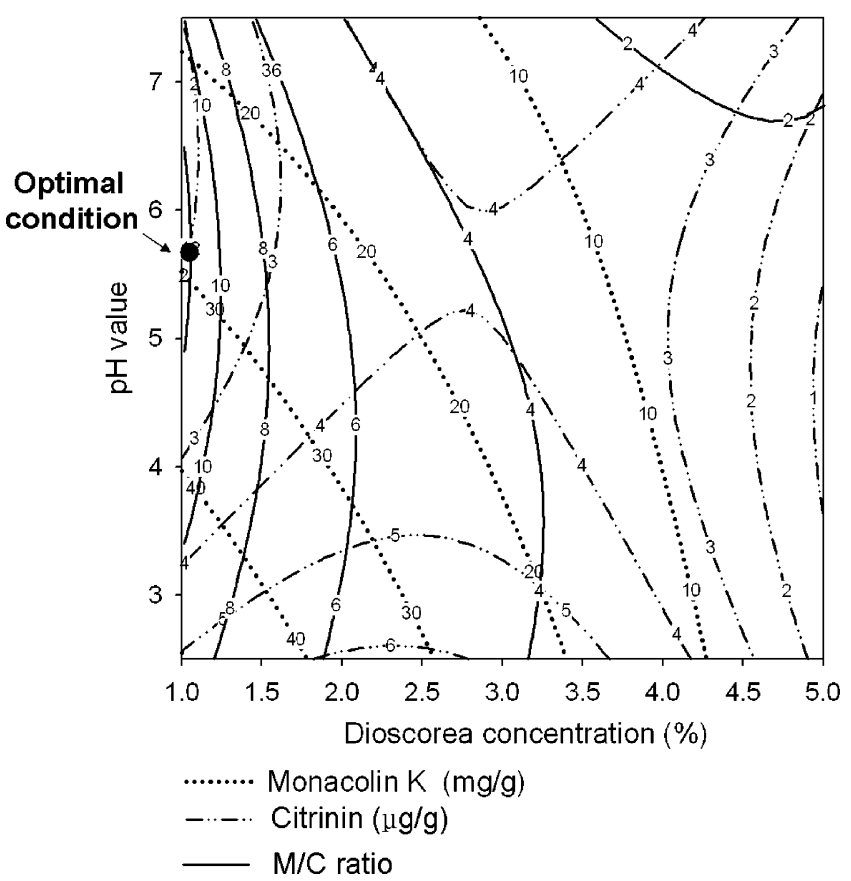

Figure 10. Overlap contour plot for monacolin $\mathrm{K}$ level, citrinin level, and for the ratio of monacolin $\mathrm{K}$ to citrinin level under various $\mathrm{pH}$ values and dioscorea concentrations (ethanol $=0.5 \%$ ).

culture and submerged culture has a similar trend and production. Furthermore, submerged culture using a jar fermentor is suitable to investigate the culture condition because stable and high reproducibility for the formation of secondary metabolite is easy to be gained.

RSM is a reliable and useful statistics methodology for the investigation of the optimal condition. RSM is usually used to investigate the effects of the condition factors on the changes of target product or markers through multiple views provided by the curve surface figure (4). This study uses RSM to investigate the effects of $\mathrm{pH}$ value, ethanol, and dioscorea concentration on the changes of monacolin $\mathrm{K}$ and citrinin levels, $\mathrm{B} / \mathrm{D}$ ratio, and $\mathrm{M} / \mathrm{C}$ ratio. The three factors ( $\mathrm{pH}$ value, ethanol and dioscorea concentrations) were demonstrated to result in a significant change in monacolin $\mathrm{K}$ and citrinin levels by this study or our previous studies $(3,4)$. Increasing ethanol concentration of medium would decrease the citrinin formation of Monascus species, but also reduce monacolin K level at the same time. According to the results of RSM, both citrinin and monacolin $\mathrm{K}$ levels would be decreased by increasing ethanol concentration. However, the ethanol-induced effects were not the cause of the reduction of cell amount but the interference of polyketide metabolism. Half percentage ethanol concentration is the most suitable condition for obtaining a higher $\mathrm{M} / \mathrm{C}$ ratio.

Although dioscorea provides the source of carbon and nitrogen for the growth of Monascus species, monacolin K concentration would not be increased by increasing dioscorea concentration. In contrast, RSM results indicated that the monacolin $\mathrm{K}$ concentration of RMD would be diluted by the increasing dioscorea added because too much dioscorea was unable to be completely consumed by Monascus species. The biggest change caused by dioscorea concentration is $\mathrm{M} / \mathrm{C}$ ratio in which higher monacolin $\mathrm{K}$ and lower citrinin levels could be obtained under $1 \%$ dioscorea concentration.

The commercial dioscorea root with low $\mathrm{pH}$ value (3.0) resulted from the pretreatment with citrate solution to prevent the browning (15). However, this food process may cause $M$. purpureus NTU 568 to produce high monacolin K production 
Table 5. Effect of Culture Conditions on the Production of Monacolin K, Citrinin, and the Ratio of Monacolin K to Citrinin Level by Monascus purpureus NTU 568

\begin{tabular}{|c|c|c|c|c|c|c|}
\hline \multicolumn{4}{|c|}{ culture condition } & \multicolumn{3}{|c|}{ effector } \\
\hline medium & $\mathrm{pH}$ range & $\begin{array}{c}\text { substrate } \\
(\%)\end{array}$ & $\begin{array}{c}\text { ethanol } \\
(\%)\end{array}$ & $\begin{array}{c}\underset{(\mathrm{mg} / \mathrm{g})}{\operatorname{monacolin} \mathrm{K}} \\
\text {. }\end{array}$ & $\begin{array}{l}\text { citrinin } \\
(\mu \mathrm{g} / \mathrm{g})\end{array}$ & $\begin{array}{l}\mathrm{M} / \mathrm{C} \\
\text { ratio }^{b}\end{array}$ \\
\hline $\begin{array}{l}\text { rice } \\
\text { dioscorea } \\
\text { dioscorea }\end{array}$ & $\begin{array}{l}5.7-7.2 \\
3.0-3.2 \\
5.7\end{array}$ & $\begin{array}{l}5 \\
5 \\
1\end{array}$ & 0.5 & $\begin{array}{r}7.62 \\
18.92 \\
27.90\end{array}$ & $\begin{array}{l}1.89 \\
4.67 \\
2.15\end{array}$ & $\begin{array}{r}4.03 \\
4.05 \\
12.98\end{array}$ \\
\hline
\end{tabular}

${ }^{a}$ The optimal culture condition based on RSM. ${ }^{b}$ The ratio of monacolin $\mathrm{K}$ to citrinin level.

at $18.92 \mathrm{mg} / \mathrm{g}$ under dioscorea medium. Fixing the $\mathrm{pH}$ value of rice medium at 3.0 also increased the monacolin $\mathrm{K}$ production to $13.3 \mathrm{mg} / \mathrm{g}$. Fermentation condition with low $\mathrm{pH}$ value is probable to stimulate monacolin $\mathrm{K}$ formation even though it cannot be equal to that obtained under dioscorea medium. However, $\mathrm{pH}$ value condition is certainly one of the major reasons for modulating monacolin $\mathrm{K}$ production. The result of RSM clearly indicates that higher monacolin $\mathrm{K}$ formation induced by lower $\mathrm{pH}$ value was due to the increase of Monascus cell amount. Monascus species is able to grow at the $\mathrm{pH}$ value among 2.5-10.0. Previous researchers proved that the various types of Monascus pigments would be formed with the change of $\mathrm{pH}$ culture condition (16). Carels and Shepherd suggested that lowering the $\mathrm{pH}$ value to 2.5 would increase the formation of yellow and orange pigment (27). Monacolin K, citrinin, and the pigments are the derivatives of polyketide so the $\mathrm{pH}$ condition should also affect the formation of monacolin $\mathrm{K}$ and citrinin. Lower $\mathrm{pH}$ value under 4.5 was used as the culture condition to investigate the production of monacolin $\mathrm{K}$ and citrinin by Monascus-related studies. However, lowering the $\mathrm{pH}$ value resulted in higher monacolin $\mathrm{K}$ level, but also higher citrinin level. The optimal culture condition based on RSM results indicates that a $\mathrm{pH}$ value at 5.7 is a suitable condition for increasing the $\mathrm{M} / \mathrm{C}$ ratio (Figure 10). This dioscorea medium without extreme $\mathrm{pH}$ value also led to higher monacolin $\mathrm{K}$ production than rice medium. This RSM result implies that the components and character of dioscorea are the important factors for stimulating monacolin $\mathrm{K}$ formation, and culture $\mathrm{pH}$ value should be considered as a sensitive factor for the modulation of Monascus cell amount and citrinin formation.

Amylose is the major type of starch in dioscorea (8). This character may result in a comfortable environment for Monascus species to grow. In addition to the composition of starch, mucilage of dioscorea includes various kinds of amino acids (aspartic acid, glutamic acid, leucine, glycine, etc.) and carbohydrates (mannose, arabinose, glucose, xylose, and rhamnose) $(10,11)$. Therefore, the mucilage including enough carbon and nitrogen sources can be quickly consumed and used by Monascus species. Furthermore, the optimal culture condition without lower $\mathrm{pH}$ value under 3.0 still results in high monacolin $\mathrm{K}$ formation at $27.90 \mathrm{mg} / \mathrm{g}$ and low citrinin formation at 2.15 $\mu \mathrm{g} / \mathrm{g}$. Therefore, this study suggests that dioscorea stimulating monacolin $\mathrm{K}$ formation is probably due to its composition and character, but $\mathrm{pH}$ condition should be an important modulator for obtaining RMD with high $\mathrm{M} / \mathrm{C}$ ratio.

Dioscorea medium with low $\mathrm{pH}$ value at 3.5 was found to significantly stimulate monacolin K formation by $148 \%$ but also increase citrinin level by $147 \%$, as compared to rice medium. Culture $\mathrm{pH}$ value, dioscorea concentration, and ethanol concentration were used as the factors of RSM to investigate the optimal culture condition for high monacolin $\mathrm{K}$ production and low citrinin formation. In the results, the $\mathrm{pH}$ value of dioscorea medium was involved in the formation of Monascus cell amount and secondary metabolite. RSM results further indicated that lowering the $\mathrm{pH}$ value to 2.5 would result in high monacolin $\mathrm{K}$ and citrinin concentration as well as large biomass in fixed dioscorea amount, implying that $\mathrm{pH}$ value may stimulate the formation of monacolin $\mathrm{K}$ and citrinin through increasing Monascus cell amount. However, the composition and character of dioscorea should be the important factors for the mediation of monacolin $\mathrm{K}$ formation in addition to $\mathrm{pH}$ value. Lowering dioscorea and ethanol concentration was able to increase the ratio of monacolin $\mathrm{K}$ level to citrinin level. The optimal culture

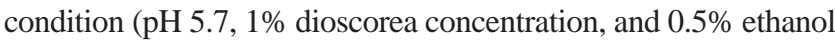
concentration) would increase monacolin $\mathrm{K}$ level to $27.9 \mathrm{mg} / \mathrm{g}$ (by $47 \%$ ) and decrease citrinin level to $2.15 \mu \mathrm{g} / \mathrm{g}$ (by $54 \%$ ), as

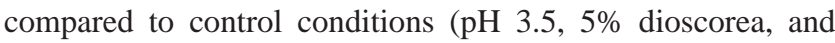
ethanol free).

\section{LITERATURE CITED}

(1) Lee, C. L.; Tsai, T. Y.; Wang, J. J.; Pan, T. M. In vivo hypolipidemic effects and safety of low dosage Monascus powder in a hamster model of hyperlipidemia. Appl. Microbiol. Biotechnol. 2006, 70, 533-540.

(2) Li, C. L.; Zhu, Y.; Wang, Y. Y.; Zhu, J. S.; Chang, J.; Kritchevsky, D. Monascus purpureus-fermented rice (red yeast rice): a natural food product that lowers blood cholesterol in animal models of hypercholesterolemia. Nutr. Res. 1998, 18, 7181.

(3) Lee, C. L.; Wang, J. J.; Kuo, S. L.; Pan, T. M. Monascus fermentation of dioscorea for increasing the production of cholesterol-lowering agent-monacolin $\mathrm{K}$ and antiinflammation agent-monascin. Appl. Microbiol. Biotechnol. 2006, 72, 12541262.

(4) Wang, J. J.; Lee, C. L.; Pan, T. M. Improvement of monacolin $\mathrm{K}$, gamma-aminobutyric acid and citrinin production ratio as a function of environmental conditions of Monascus purpureus NTU 601. J. Ind. Microbiol. Biotechnol. 2003, 30, 669-676.

(5) Wang, J. J.; Lee, C. L.; Pan, T. M. Modified mutation method for screening low citrinin-producing strains of Monascus purpureus on rice culture. J. Agric. Food Chem. 2004, 52, 69776982.

(6) Rosenblitt, A.; Agosin, E.; Delgado, J.; Perez-Correa, R. Solid substrate fermentation of Monascus purpureus: growth, carbon balance, and consistency analysis. Biotechnol. Prog. 2000, 16, $152-162$.

(7) Ju, J. Y.; Shin, C. S.; Whitcombe, M. J.; Vulfson, E. N. Imprinted polymers as tools for the recovery of secondary metabolites produced by fermentation. Biotechnol. Bioeng. 1999, 64, 232239.

(8) Wanasundera, J. P.; Ravindran, G. Nutritional assessment of yam (Dioscorea alata) tubers. Plant Foods Hum. Nutr. 1994, 46, $33-$ 39.

(9) Hoover, R. Composition, molecular structure, and physicochemical properties of tuber and root starches: a review. Carbohydr. Polym. 2001, 45, 253-267. 
(10) Tomoda, M.; Ishikawa, K.; Yokoi, M. Plant mucilages. Isolation and characterization of a mucilage, "Dioscorea-mucilage B," from the rhizophors of Dioscorea batatas. Chem. Pharm. Bull. 1981, 29, 3256-3261.

(11) Misaki, A.; Ito, T.; Harada, T. Constitutional studies on the mucilage of yamanoimo, Dioscorea batatas Decne, forma Tsukune. Isolation and structure of a mannan. Agric. Biol. Chem. 1972, 36, 761-771.

(12) Lin, W. Y.; Ting, Y. C.; Pan, T. M. Proteomic response to intracellular proteins of Monascus pilosus grown under phosphatelimited complex medium with different growth rates and pigment production. J. Agric. Food Chem. 2007, 55, 467-474.

(13) Juzlova, P.; Martinkova, L.; Kren, V. Secondary metabolites of the fungus Monascus: a review. J. Ind. Microbiol. 1996, 16, $163-170$

(14) Hajjaj, H.; Klaebe, A.; Loret, M. O.; Goma, G.; Blanc, P. J.; Francois, J. Biosynthetic pathway of citrinin in the filamentous fungus Monascus ruber as revealed by ${ }^{13} \mathrm{C}$ nuclear magnetic resonance. Appl. Environ. Microbiol. 1999, 65, 311-314.

(15) Quattrucci, E.; Masci, V. Nutritional aspects of food preservatives. Food Addit. Contam. 1992, 9, 515-525.

(16) Carels, M.; Shepherd, D. The effect of changes in $\mathrm{pH}$ on phosphate and potassium uptake by Monascus rubiginosus ATCC 16367 in submerged shaken culture. Can. J. Microbiol. 1979, $25,1484-1488$

(17) Tseng, Y. Y.; Chen, M. T.; Lin, C. F. Growth, pigment production and protease activity of Monascus purpureus as affected by salt, sodium nitrite, polyphosphate and various sugars. J. Appl. Microbiol. 2000, 88, 31-37.

(18) Lee, C. L.; Wang, J. J.; Pan, T. M. Synchronous analysis method for detection of citrinin and the lactone and acid forms of monacolin $\mathrm{K}$ in red mold rice. J. AOAC Int. 2006, 89, 669677.

(19) Lin, C. F.; Iizuka, H. Production of extracellular pigment by a mutant of Monascus kaoliang sp. nov. Appl. Environ. Microbiol. 1982, 43, 671-676.
(20) Box, G. E. P.; Behnken, D. W. Some new three level designs for the study of quantitative variable. Technometrics 1960, 2 , 455-463.

(21) Giovanni, M. Response surface methodology and product optimization. 1983, 37, 96-105.

(22) Sayyad, S. A.; Panda, B. P.; Javed, S.; Ali, M. Optimization of nutrient parameters for lovastatin production by Monascus purpureus MTCC 369 under submerged fermentation using response surface methodology. Appl. Microbiol. Biotechnol. 2007, 73, 1054-1058.

(23) Li, F. Q.; Xu, G. R.; Li, Y. W.; Chen, Y.; Ji, R. Natural occurrence of citrinin in Monascus products. Wei. Sheng. Yan. Jiu. 2005, 34, 451-454.

(24) Wang, J. J.; Shieh, M. J.; Kuo, S. L.; Lee, C. L.; Pan, T. M. Effect of red mold rice on antifatigue and exercise-related changes in lipid peroxidation in endurance exercise. Appl. Microbiol. Biotechnol. 2006, 70, 247-253.

(25) Heber, D.; Yip, I.; Ashley, J. M.; Elashoff, D. A.; Elashoff, R. M.; Go, V. L. Cholesterol-lowering effects of a proprietary Chinese red-yeast-rice dietary supplement. Am. J. Clin. Nutr. 1999, 69, 231-236.

(26) Su, N. W.; Lin, Y. L.; Lee, M. H.; Ho, C. Y. Ankaflavin from Monascus-fermented red rice exhibits selective cytotoxic effect and induces cell death on Hep G2 cells. J. Agric. Food Chem. 2005, 53, 1949-1954.

(27) Carels, M.; Shepherd, D. The effect of $\mathrm{pH}$ and amino acids on conidiation and pigment production of Monascus major ATCC 16362 and Monascus rubiginosus ATCC 16367 in submerged shaken culture. Can. J. Microbiol. 1978, 24, 1346-1357.

Received for review April 23, 2007. Revised manuscript received June 3, 2007. Accepted June 12, 2007.

JF0711946 